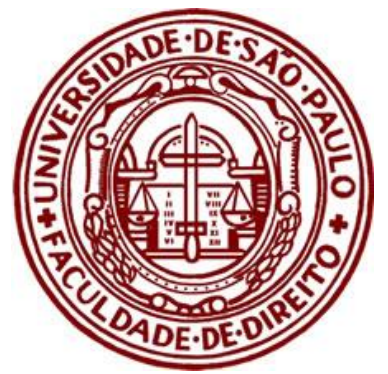

PAULO ALVES NETTO DE ARAUJO

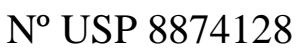

\title{
Omissão Inconstitucional: Teoria e Prática
}

Dissertação de Mestrado

Orientadora: Professora Associada Doutora Anna Candida da Cunha Ferraz

UNIVERSIDADE DE SÃO PAULO

FACULDADE DE DIREITO

SÃO PAULO

2017 
PAULO ALVES NETTO DE ARAUJO

$\mathrm{N}^{\circ}$ USP 8874128

\section{Omissão Inconstitucional: Teoria e Prática}

Dissertação de Mestrado, apresentada à Banca

Examinadora do Programa de Pós-Graduação em Direito, da Faculdade de Direito da Universidade de São Paulo, como exigência parcial para a obtenção do título de Mestre em Direito, na área de concentração de Direito do Estado, sob a orientação da Professora Associada Doutora Anna Candida da Cunha Ferraz.

UNIVERSIDADE DE SÃO PAULO

FACULDADE DE DIREITO

SÃO PAULO

2017 
Catalogaçẫo da Publicaçẫo

Serviço de Biblioteca e Documentaçẫo

Faculdade de Direito da Universidade de Sẫo Paulo

Araujo, Paulo Alves Netto de

Omissão inconstitucional teoria e prătica; /

Paulo alves Netto de Araujo; orientador Anna

Candida da Cunha Ferraz - - São Paulo, 2017.

$188 \mathrm{f}$.

Dissertaçâ̊ (Mestrado - Programa de Pós-Graduaçấ em Direito do Estado) - Faculdade de Direito.

Universidade de Să̊ Paulo, 2017.

1. Direito Constitucional. 2. Controle de Constitucionalidade. 3. Omissấ Legislativa. 4. Inconstitucionalidade. I. Ferraz, anna Candida da Cunha, orient. II. Título. 
Nome: Araujo, Paulo Alves Netto de.

Título: Omissão Inconstitucional: Teoria e Prática

Dissertação de Mestrado, apresentada à Banca

Examinadora do Programa de Pós-Graduação em Direito, da Faculdade de Direito da Universidade de São Paulo, como exigência parcial para a obtenção do título de Mestre em Direito, na área de concentração de Direito do Estado, sob a orientação da Professora Associada Doutora Anna Candida da Cunha Ferraz.

Prof. Dr.

Instituição

Julgamento Assinatura

Prof. Dr. Instituição

Julgamento Assinatura

Prof. Dr. Instituição Julgamento Assinatura 


\section{AGRADECIMENTOS}

Ao finalizar este trabalho, tenho muito a agradecer.

Em primeiro lugar, a Deus, pela oportunidade de cursar o Mestrado na gloriosa Faculdade de Direito da Universidade de São Paulo e poder, com este trabalho, modestamente, contribuir para o aprimoramento do estudo do Direito Constitucional no Brasil.

Aos meus colegas de curso, pela rica troca de experiências e de visões de mundo que me proporcionaram.

Aos professores, pelo valioso conhecimento que me transmitiram, que muito me auxiliou na elaboração deste trabalho.

À professora Anna Candida da Cunha Ferraz, que, desde o início do curso, sempre me transmitiu valorosas lições, de Direito e de vida e que me orientou de maneira brilhante, mesmo antes de ser iniciada a escrita deste trabalho.

A meus pais, pelos exemplos de vida, honestidade e perseverança, que me impulsionaram até esta etapa de minha vida.

A meu pai, pelo exemplo de carreira acadêmica, que sempre me inspira e pelas valorosas sugestões, muito importantes para o desenvolvimento deste trabalho. 
Aos meus filhos, João Victor e Felipe, pelos votos de sucesso que sempre me deram e pela compreensão pelas horas de convívio das quais abrimos mão em prol de meus estudos.

Finalmente, à minha querida esposa Mariangela, companheira de todas as horas, cujo amor incondicional me dá forças para enfrentar as dificuldades do dia-a-dia, que sempre me impulsionou a seguir em frente, mesmo quando os obstáculos pareciam impossíveis de ser vencidos, foi minha maior incentivadora e sempre acreditou que era possível cumprir esta missão. 


\section{RESUMO}

ARAUJO, Paulo Alves Netto. Omissão inconstitucional: teoria e prática. 2017.

f. Dissertação (Mestrado) - Faculdade de Direito, Universidade de São Paulo, São Paulo, 2017.

No controle de constitucionalidade, a concretização dos dispositivos constitucionais é uma questão que sempre preocupou os estudiosos do Direito Constitucional, no Brasil e também em outros países. A ausência de providências legislativas, regulamentares e administrativas, por parte dos ramos estatais do Poder, necessárias a esta concretização, é uma problemática que permanece atual, especialmente se pensarmos em Constituições analíticas, como a Constituição brasileira de 1988. O objeto deste trabalho é a análise da omissão inconstitucional, no Brasil e em outros países, dos instrumentos de controle, da eficácia de tais instrumentos e se a existência deles ainda se justifica no atual panorama do Direito Constitucional brasileiro. Deste modo, o primeiro capítulo analisa a figura da omissão inconstitucional, seus pressupostos, características, causas, a eficácia e aplicabilidade das normas constitucionais e sua repercussão na caracterização da omissão, as modalidades de omissão e a omissão em relação a direitos fundamentais. O segundo capítulo analisa alguns sistemas estrangeiros de controle de constitucionalidade e de que forma a omissão inconstitucional é tratada nesses países. O terceiro capítulo analisa o sistema de controle das omissões, no plano constitucional federal. O quarto capítulo analisa o sistema de controle das omissões nos Estados-Membros e seus reflexos nos Municípios. O quinto capítulo analisa a eficácia dos instrumentos de controle nos planos federal e estadual. A conclusão é que estes instrumentos ainda exercem um papel importante na superação das omissões inconstitucionais.

PALAVRAS-CHAVE: Controle de Constitucionalidade - Concretização Omissão Legislativa - Inconstitucionalidade 


\begin{abstract}
ARAUJO, Paulo Alves Netto. Omission unconstitutional: theory and practice. 2017. f. Dissertation (maester) - Faculty of Law, University of São Paulo, São Paulo, 2017.

In the control of constitutionality, the achievement of constitutional devices is a question that always worried the scholars of constitutional law, in Brazil and also in other countries. The absence of laws, regulations and administrative measures by the State Power branches, necessary to this implementation, is one problem that remains current, especially if we think of Constitutions, as the brazilian Constitution of 1988. The object of this work is the analysis of unconstitutional omission in Brazil, and in other countries, the instruments of control, the effectiveness of such instruments and if their existence still justified in the current panorama of Brazilian constitutional law. In this way, the first chapter analyzes the figure of unconstitutional omission, its assumptions, characteristics, causes, the effectiveness and applicability of constitutional standards and their impact on the characterization of the omission, the procedures for oversight and omission in relation to fundamental rights. The second chapter analyzes some foreign systems of control of constitutionality and how unconstitutional omission is treated in these countries. The third chapter analyzes the control system of the omissions in the federal constitutional plan. The fourth chapter examines the control system of the omissions in the Member States and their reflections in the municipalities. The fifth chapter analyzes the effectiveness of the instruments of control in federal and State plans. The conclusion is that these instruments still play a major role in overcoming the unconstitutional omissions.
\end{abstract}

KEYWORDS: Control of Constitutionality - Implementation - Legislative Omission-Unconstitutionality 


\section{INTRODUÇÃO.}

Com a presente dissertação, pretendemos oferecer à comunidade acadêmica um panorama atual da omissão inconstitucional no Brasil e também em outros países, em breve análise comparativa, sem a pretensão de esgotar o tema.

Para atingir este objetivo, serão pesquisadas não só obras de autores brasileiros, mas também obras estrangeiras, algumas delas em edições traduzidas para o português, para melhor situar o tema.

Assim, partiremos de um pressuposto considerado fundamental e anterior à problemática da omissão inconstitucional, qual seja, a teoria a respeito da concretização de dispositivos constitucionais.

Como a concretização ocorre por meio da aplicação direta do texto constitucional, pela atuação do legislador infraconstitucional, do poder regulamentar e, eventualmente, pela jurisprudência, iniciaremos o trabalho pelo estudo dos Princípios de interpretação do Direito Constitucional e da relação de tais princípios com o tema deste trabalho.

Buscaremos, a partir desse exame, utilizar um conceito inicial de omissão inconstitucional e, a partir daí, identificar as causas do surgimento dessa figura e o tipo de norma que reclama complementação legislativa ou regulamentar.

Destacamos que, neste trabalho, também analisaremos a omissão inconstitucional com relação à concretização dos direitos fundamentais, problemática intensamente tratada na doutrina e na jurisprudência. 
Examinaremos, também, sem a pretensão de esgotar uma análise comparativa, a admissão da omissão inconstitucional em outros ordenamentos jurídicos, os pressupostos e as possíveis diferenças ou semelhanças apresentadas, com relação à adoção da figura da omissão inconstitucional no Brasil.

Em seguida, trataremos dos instrumentos específicos de controle da omissão inconstitucional no Brasil, seja no âmbito da Constituição Federal, seja no das Constituições estaduais, e sua possível repercussão na esfera municipal.

Nesta análise, procuraremos, também, verificar, na doutrina e na jurisprudência, se, após quase trinta anos da promulgação da Constituição Federal de 1988 e das Constituições dos Estados-Membros, todas as omissões inconstitucionais nelas identificáveis foram sanadas ou se ainda persistem dispositivos constitucionais não regulamentados, que justifiquem a permanência dos instrumentos de controle, aparentemente instituídos para vigorarem enquanto a Constituição não tiver suas normas totalmente cumpridas.

Por fim, buscaremos verificar se os instrumentos de controle da omissão inconstitucional no Brasil são eficazes e se sua existência ainda se justifica.

Ao final, apresentaremos as conclusões que surgirem a partir dos estudos que serão realizados. 


\section{SUMÁRIO:}

INTRODUÇÃO

1 - OS PRESSUPOSTOS DA OMISSÃO INCONSTITUCIONAL..............15

2- CARACTERÍSTICAS DA OMISS ÃO.............................................17

3- CAUSAS DA OMISSÃO..................................................................26

4- EFICÁCIA E APLICABILIDADE DAS NORMAS CONSTITUCIONAIS

E SUA REPERCUSSÃO NA CARACTERIZAÇÃO DA OMISSÃO.........33

5- MODALIDADES DE OMISSÃO INCONSTITUCIONAL....................52

6- OMISSÃO EM RELAÇÃO A DIREITOS FUNDAMENTAIS...............55

\section{II - CONSIDERAÇÕES A RESPEITO DE ALGUNS SISTEMAS}

\section{DE CONTROLE DAS OMISSÕES NO DIREITO}

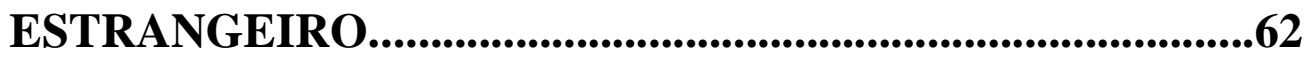

1- DIREITO DO REINO UNIDO................................................63

2- DIREITO NORTE-AMERICANO..........................................65

3- DIREITO PORTUGUÊS..........................................................68

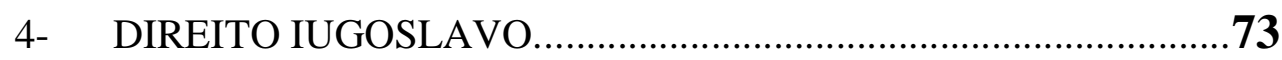

5- DIREITO ITALIANO _.............................................................

6- DIREITO ALEMÃO..............................................................79

7- DIREITO ESPANHOL...........................................................84

8- DIREITO FRANCÊS.........................................................87

9- DIREITO ARGENTINO.......................................................88

10- DIREITO PERUANO.............................................................92

11- CONCLUSÕES DO ITEM.....................................................95 


\section{III - SISTEMA DE CONTROLE DAS OMISSÕES INCONSTITUCIONAIS, NO PLANO FEDERAL......................96}

1- INSTRUMENTOS DE CONTROLE: O MANDADO DE INJUNÇÃO E A AÇÃO DIRETA DE INCONSTITUCIONALIDADE POR OMISSÃO ADO. . .97

2 - ORIGEM HISTÓRICA E CARACTERÍSTICAS DO MANDADO DE INJUNÇÃO. 101

2.1 - NATUREZA DO INSTRUMENTO. 104

2.2 - A APLICABILIDADE DO INSTRUMENTO. 106

2.3 - PROCEDIMENTO. 108

2.4 - BREVE EXAME DOS PROJETOS DE LEI APRESENTADOS AO CONGRESSO NACIONAL COM O OBJETIVO DE REGULAMENTAR O MANDADO DE INJUNÇÃO. 110

2.5 - CRÍTICAS DA DOUTRINA A RESPEITO DO PROJETO DE LEI N ${ }^{\circ}$ 6.129, DE 2009. 112

2.6 - A JURISPRUDÊNCIA DOMINANTE NO STF ATÉ A ENTRADA EM VIGOR DA LEI FEDERAL No 13.300, DE 23-06-2016. 119

2.7 - A LEI FEDERAL N ${ }^{\circ}$ 13.300/2016 E SUA APLICAÇÃO. 121

3 - BREVE ANÁLISE SOBRE A AÇÃO DIRETA DE INCONSTITUCIONALIDADE POR OMISSÃO - ADO.

\section{IV - OMISSÃO INCONSTITUCIONAL NOS ESTADOS E SEUS REFLEXOS NO PLANO DOS MUNICÍPIOS..............................127}

1 - CONSIDERAÇÕES PRELIMINARES 128

2 - MODELOS DE CONTROLE DE CONSTITUCIONALIDADE ESTADUAL ANTERIORES À CONSTITUIÇÃO DE 1988. 133

2.1 - CONSTITUIÇÃO DE 1946, APÓS A EMENDA CONSTITUCIONAL N. 16, DE 1965. 133 
2.2 - CONSTITUIÇÃO DE 1967, APÓS A EMENDA CONSTITUCIONAL N. 1, DE 1969....................................................136

$2.3-$ MODELO DE CONTROLE CONCENTRADO DE CONSTITUCIONALIDADE ESTADUAL PREVISTO NA CONSTITUIÇÃO DE 1988. 138

$2.4 \quad-\quad$ MODELO DE $\quad$ CONTROLE DIFUSO DE CONSTITUCIONALIDADE ESTADUAL PREVISTO NA CONSTITUIÇÃO DE 1988

1 - CONTROLE DA OMISSÃO INCONSTITUCIONAL EM RELAÇÃO À CONSTITUIÇÃO FEDERAL. 150

1.1 - DISPOSITIVOS CONSTITUCIONAIS FEDERAIS AINDA NÃO REGULAMENTADOS 150

2 - CONTROLE DAS OMISSÕES INCONSTITUCIONAIS NO PLANO ESTADUAL E SEUS REFLEXOS NO PLANO MUNICIPAL .157

2.1 - OMISSÕES NOS ESTADOS E MUNICÍPIOS EM RELAÇÃO À CONSTITUIÇÃO FEDERAL .157

2.2 - OMISSÕES NOS ESTADOS E MUNICÍPIOS EM RELAÇÃO À CONSTITUIÇÃO ESTADUAL 164

2.3 - DISPOSITIVOS CONSTITUCIONAIS ESTADUAIS AINDA NÃO REGULAMENTADOS 167

3 - A EFETIVIDADE DO CONTROLE DA OMISSÃO NOS PLANOS FEDERAL E ESTADUAL E SEUS REFLEXOS NOS MUNICÍPIOS......170

VI - CONCLUSÕES. 174

VII - REFERÊNCIAS BIBLIOGRÁFICAS .179 


\title{
I - CONSIDERAÇÕES INICIAIS SOBRE A OMISSÃO INCONSTITUCIONAL.
}

\author{
No item 1, serão estudados os pressupostos da omissão \\ inconstitucional.
}

No item 2, serão estudadas as características da omissão, bem como quais são os entes estatais omissos e as razões dessa omissão, verificando se há ou não omissão deliberada.

No item 3, estudaremos as modalidades de omissão inconstitucional mencionadas pela doutrina.

No item 4, estudaremos a questão da eficácia e aplicabilidade das normas constitucionais, para identificarmos que tipo de norma constitucional necessita de complementação para adquirir plena eficácia.

No item 5, estudaremos as modalidades de omissão inconstitucional.

No item 6, trataremos da omissão em relação a direitos fundamentais, verificando a necessidade ou não de complementação legislativa ou regulamentar para as normas constitucionais que tratam do tema, as quais, em princípio, poderiam ser aplicadas diretamente a partir do texto constitucional. 


\section{VI- CONCLUSÕES.}

1- A concretização dos dispositivos constitucionais pode ocorrer por meio da interpretação constitucional, com a aplicação direta de seus dispositivos, quando a norma constitucional a permite e por meio de complementação normativa ou regulamentar, para os dispositivos constitucionais que a exijam;

2 - Em relação ao tema, verificamos que guardam relação com o estudo da omissão os Princípios da Unidade da Constituição, Exatidão Funcional, Proporcionalidade e Razoabilidade, Supremacia da Constituição, Força Normativa da Constituição, bem como os subprincípios da Máxima Eficácia e Efetividade;

3 - Inicialmente, concluímos que a omissão inconstitucional ocorre quando os poderes constituídos, conscientemente, não cumprem as determinações constitucionais para a complementação dos dispositivos constitucionais que assim o exijam.

4 - A omissão é causada, principalmente, pela inércia consciente do Poder Legislativo na edição das normas infraconstitucionais necessárias à concretização de determinados dispositivos constitucionais, durante certo tempo;

5 - Nas hipóteses onde a Constituição estabeleceu prazos para a complementação normativa, a omissão surge após o decurso de tais prazos, sem que a regulamentação tenha ocorrido, ao passo que, se não houver prazo fixado, deve ser levado em consideração determinado período de tempo para considerarmos que os poderes competentes estão em mora constitucional;

6 - Mais uma causa desta omissão é o excessivo idealismo da Constituição brasileira, onde há dispositivos cuja aplicação prática é difícil, como na questão do valor do salário mínimo; 
7 - Os maiores problemas referentes ao tema, segundo os doutrinadores citados neste trabalho, são a inexistência de instrumentos hábeis a obrigar o Poder Legislativo a cumprir seu papel (problema que já ocorria antes da promulgação do texto constitucional de 1988, tanto que, no início da aplicação da Ação Direta de Inconstitucionalidade por Omissão e do Mandado de Injunção, as decisões proferidas pelo STF tinham caráter meramente declaratório, comunicando ao poder competente sua omissão no cumprimento do mandamento constitucional para legislar) e a não atribuição de prazo para o cumprimento da determinação constitucional;

8 - Em relação à omissão inconstitucional provocada pela inércia do Poder Executivo, o instrumento hábil a compelir esse poder a suprir sua inércia é a decisão judicial proferida em Mandado de Injunção ou Ação Direta de Inconstitucionalidade por Omissão, que poderá fixar prazo para que seja editada a norma jurídica exigida.

Nesse sentido, o $\S 1^{\circ}$ do artigo $4^{\circ}$ da Constituição do Estado de Minas Gerais, é pioneiro, pois instituiu dispositivo que procura obrigar o poder público a agir, onde estão previstas as penas de destituição de mandato administrativo ou perda de cargo ou função de direção, aos servidores da Administração que deixarem de sanar em noventa dias da data do requerimento do interessado, omissão que impeça o exercício de direito constitucional.

9 - Permanece, contudo, sem sanção, o comportamento inconstitucional do Poder Legislativo;

10 - Após analisar a questão da eficácia e aplicabilidade das normas constitucionais, concluímos, adotando o posicionamento de José Afonso da Silva, que é em relação às normas constitucionais de eficácia limitada, de princípio institutivo e de caráter impositivo que pode surgir o problema da omissão inconstitucional; 
11 - Quanto às modalidades de omissão, tanto na doutrina brasileira quanto na estrangeira, existem somente dois tipos, que são a omissão total, constatada quando não ocorreu qualquer complementação legislativa ou regulamentar e a omissão parcial (também chamada de omissão relativa), que se configura quando o poder responsável pela elaboração normativa ou regulamentar concretiza o dispositivo constitucional de forma incompleta ou defeituosa;

12 - A regulamentação exigida pela Constituição não é faculdade, mas sim obrigação imposta ao legislador;

13 - Ao analisarmos a eficácia dos direitos fundamentais, concluímos que, apesar da possibilidade de fruição direta de tais direitos, não há impedimento à atuação legislativa, que é necessária, de modo a reforçar o grau de eficácia de tais dispositivos, que são, também, exigíveis em Juízo, no caso de omissão legislativa inconstitucional, por meio de Mandado de Injunção;

14 - Quaisquer normas constitucionais que confiram direitos e prerrogativas às pessoas, podem ser objeto de Mandado de Injunção, ao passo que quaisquer normas constitucionais que determinem a elaboração de lei ou regulamento e que não digam respeito a direitos ou prerrogativas conferidas à pessoa, podem ser objeto de Ação Direta de Inconstitucionalidade por omissão;

15 - Nos ordenamentos jurídicos estrangeiros analisados, constatamos que há referências ao problema e a instrumentos que possibilitem sua superação somente no Brasil, em Portugal, na Argentina e no Peru; nos demais, a solução da omissão decorre de construção doutrinária e jurisprudencial, como verificamos na Alemanha, Itália e Espanha;

16 - Dentre os sistemas analisados, o que mais se aproxima do sistema brasileiro no tratamento desta questão é o sistema vigente em Portugal, que foi a grande fonte de inspiração dos constituintes brasileiros nesta matéria; 
17 - Os instrumentos judiciais de controle analisados são o Mandado de Injunção e a Ação Direta de Inconstitucionalidade por Omissão que surgiram no texto de 1988, mas a inexistência de instrumentos hábeis a superar a inconstitucionalidade por omissão já era uma preocupação da doutrina, ao tempo do regime constitucional anterior, tendo sido proposta a adoção de diversos instrumentos, mas foram somente estes os materializados na Constituição Federal de 1988;

18 - Quanto à origem do Mandado de Injunção, a maior parte da doutrina entende que o instrumento não tem similar em outros ordenamentos jurídicos e que, atualmente, os contornos do Instituto vêm sendo aprimorados e desenvolvidos nas decisões do STF e de outros tribunais brasileiros, nos diversos Mandados de Injunção ajuizados desde a promulgação do texto de 1988;

19 - A Lei federal $n^{\circ}$ 13.300, de 23-06-2016, que regulamentou o Mandado de Injunção, abarcou toda a evolução jurisprudencial do Mandado de Injunção e, nesse sentido, foi uma medida bastante positiva e que poderá sanar as dúvidas porventura existentes no tratamento processual da matéria;

20 - O parágrafo $1^{\circ}$ do artigo $9^{\circ}$ e o artigo 12 da referida Lei federal são inconstitucionais, pois permitem a transformação do Mandado de Injunção em instrumento de controle abstrato, objetivo e coletivo, em desacordo com a previsão da Constituição Federal que criou o Mandado de Injunção como instrumento de controle concreto, subjetivo e individual;

21 - A omissão inconstitucional também ocorre em relação aos ramos do Poder estaduais, pela não reprodução de dispositivos da Constituição Federal que obrigatoriamente deveriam constar das Constituições Estaduais e pela inércia na regulamentação estadual de dispositivos aos quais a Constituição Federal impôs tarefas legislativas referentes aos entes federados e aos Municípios;

22 - Em todas as Constituições estaduais foram criados instrumentos de controle da inconstitucionalidade por omissão, exigida nos textos constitucionais estatuais apenas a ampla legitimidade ativa para a utilização de tais instrumentos; 
23- Nos Estados-Membros, os instrumentos de controle criados foram a Ação Direta de Inconstitucionalidade estadual e o Mandado de Injunção estadual;

24 - Há mais dispositivos da Constituição federal que ainda aguardam regulamentação, ao passo que, nas Constituições estaduais, seus ramos de poder avançaram mais nesta matéria, editando maior número de normas regulamentadoras;

25 - Tanto em relação à Constituição Federal quanto em relação às Constituições estaduais, foi ajuizado um número maior de Mandados de Injunção do que de Ações Diretas de Inconstitucionalidade por Omissão;

26 - Todo o panorama analisado neste trabalho revela que, ao contrário de várias opiniões, formuladas ao tempo da criação dos instrumentos de controle da omissão, tais instrumentos se revelaram eficazes e vem cumprindo seu desiderato, após um início de aplicação no qual os efeitos eram meramente declaratórios.

27 - Ainda se justifica a utilização de tais instrumentos judiciais, cuja eficácia restou demonstrada ao longo deste trabalho; 


\section{VII- REFERÊNCIAS BIBLIOGRÁFICAS.}

ALMEIDA, Fernanda Dias Menezes de. Revista de informação legislativa. V. 19, n. 76, p. 125-134, out./dez., 1982. Brasília, Senado Federal, Serviço de Informação Legislativa, 1982.

. Competências na Constituição de 1988. $4^{\mathrm{a}}$ edição. São Paulo:

Atlas, 2007.

AMARAL JÚNIOR, José Levi Mello do. Regulamentação do Mandado de Injunção. In: Mandado de Injunção: estudos sobre sua regulamentação. Organizadores: Gilmar Ferreira Mendes, André Rufino do Vale e Fábio Lima Quintas. São Paulo: Saraiva, 2013.

ANTEPROJETO DE CONSTITUIÇÃO FEDERAL - COMISSÃO AFONSO ARINOS. Disponível na Internet, no site: http://www.senado.gov.br/publicacoes/anais/constituinte/AfonsoArinos.pdf, acesso em 24-06-2015.

BARROSO, Luís Roberto. Curso de direito constitucional contemporâneo, $5^{\mathrm{a}}$ ed., Rio de Janeiro: Forense, 2015.

BIDART CAMPOS, Germán J. La justicia constitucional y la inconstitucionalidad por omisión. Anuario Jurídico, UNAM, México D.F., núm. VI, 1979.

Las omisiones constitucionales em la novíssima constitución de la Provincia de Río Negro, Buenos Aires, 1991.

BONAVIDES, Paulo. Curso de direito constitucional. $30^{\text {a }}$ ed., atualizada (em apêndice a CF/1988, com as Emendas Constitucionais até a de $\mathrm{n}^{\circ}$ 84, de 2.12.2014), São Paulo: Malheiros, 2015. 
CÂMARA DOS DEPUTADOS. Constituições dos paises do Mercosul: 1996-2000 : textos constitucionais Argentina, Bolívia, Brasil, Chile, Paraguai e Uruguai. - Brasilia : Câmara dos Deputados, Coordenação de Publicações, 2001. 508 p. - (Série ação parlamentar; n. 153).

CANOTILHO, José Joaquim Gomes. Direito constitucional e teoria da Constituição $-7^{\mathrm{a}}$ ed. (2 $2^{\mathrm{a}}$ reimpressão). Edições Almedina, 2003, Coimbra.

[et al.]. Direitos fundamentais sociais - coordenadores J.J.

Gomes Canotilho, Marcus Orione Gonçalves Correia e Érica Paula Barcha Correia. - São Paulo: Saraiva, 2010.

[et al.]. Comentários à Constituição do Brasil. São Paulo: Saraiva/Almedina, 2013.

CAPELETTI, Mauro. O controle judicial de constitucionalidade das leis no Direito comparado. $2^{\mathrm{a}}$ edição, reimpressão. Trad; Aroldo Plínio Gonçalves. Porto Alegre: Sergio Antonio Fabris Editor, 1999.

CLÉVE, Clémerson Merlin. Fiscalização abstrata de constitucionalidade no direito brasileiro. $2^{\mathrm{a}}$ ed., São Paulo: Editora Revista dos Tribunais, 1999.

CONTINENTINO, Marcelo Casseb. Uma reflexão histórica sobre o Mandado de Injunção e a eficácia subjetiva das decisões. In: Mandado de Injunção: estudos sobre sua regulamentação. Organizadores: Gilmar Ferreira Mendes, André Rufino do Vale e Fábio Lima Quintas. São Paulo: Saraiva, 2013.

DAVID, René. Os grandes sistemas do direito contemporâneo (trad. port. Hermínio A. Carvalho de Les grands systèmes du droit contemporains). $4^{\text {a }}$ ed. - São Paulo : Martins Fontes - Selo Martins, 2002. 
DINIZ, Maria Helena. Norma constitucional e seus efeitos. $8^{\mathrm{a}}$ ed., São Paulo: Saraiva, 2009.

FAVOREU, Louis. As cortes constitucionais. Introdução à edição brasileira: Cláudia Toledo, Luiz Moreira. (Tradução do original Les cours constitutiónnelles: Dunia Marinho Silva). São Paulo: Landy, 2004.

[et. al.]. Tribunales constitucionales europeos y derechos fundamentales. Madrid: Centro de Estudios Constitucionales, 2004. (Traducido por Luis Aguiar de Luque e Maria Gracia Rubio de Casas, do título original de la edición francesa: "COURS CONSTITUTIONELES EUROPENNES ET DROITS FONDAMENTAUX" bajo la dirección de Louis Favoreu, com prefacio de Andre Tunc, publicada por Presses Universitaires d' Aix-Marseille y Librairie Economica de Paris, 1982.

FELLET, André e NOVELINO, Marcelo (Org.). Constitucionalismo e Democracia. Salvador: Editora Juspodivm.

FERRAZ, Anna Candida da Cunha. Poder constituinte do estadomembro. São Paulo: Ed. Revista dos Tribunais, 1979.

A inércia no plano constitucional. Revista da Procuradoria Geral do Estado de São Paulo, São Paulo, v. 19, 1982. Processos Informais de Mudança da Constituição: mutações constitucionais e mutações inconstitucionais. 1. ed. São Paulo: Max Limonad, 1986, v. 1.

Inconstitucionalidade por omissão: uma proposta para Constituinte: Revista de Informação Legislativa, a.23, $\mathrm{n}^{\mathbf{0}} 89$, Revista de Informação Legislativa, 1986. 
- Proteção jurisdicional da omissão inconstitucional dos poderes locais. Revista mestrado em direito. Ano 5. N N $^{\circ}$. UNIFIEO. Edifieo, 2005.

FERREIRA FILHO, Manoel Gonçalves. Aplicabilidade das normas constitucionais. In: Antologia luso-brasileira de direito constitucional. Saraiva, Paulo Lopo (coord.). Brasília: Livraria e Editora Brasília Jurídica Ltda., 1992.

. Comentários à Constituição brasileira de 1988 - 2. ed. atual. e reform. - São Paulo: Saraiva, 1997, vol. 1 - arts. $1^{\circ}$ a 103.

. Curso de Direito Constitucional $-34^{\mathrm{a}}$ ed. - São Paulo: Saraiva, 2008.

. O Poder Constituinte. 6a edição- São Paulo: Saraiva, 2014.

HESSE, Konrad. Elementos de direito constitucional da República Federal da Alemanha (trad. port. de Luís Afonso Heck da $20^{\text {a }}$ edição alemã do original Grundzüge Verfassungsrechts der Bundesrepublik Deustchland). Porto Alegre: Sergio Fabris, 1998.

A força normativa da constituição (trad. port. do Ministro Gilmar Mendes do original em alemão Die Normative Kraft der Verfassung). Porto Alegre: Sergio Fabris, 2009.

JÚNIOR, Dirley da Cunha. Controle judicial das omissões do Poder Público. $2^{\mathrm{a}}$ ed., Saraiva, 2008.

LACERDA, Galeno. Revisão do conceito de federação: sistema de recursos e de ações constitucionais; abolição do mandado de injunção. Cadernos de direito constitucional e ciência política, nº 3, abr-jun 1993. 
LEÓN, Aníbal Quiroga. "El derecho procesal constitucional peruano", disponível em http://biblio.juridicas.unam.mx/libros/1/344/22.pdf, acesso em 24-06-2015.

LEONCY, Léo Ferreira. Controle de constitucionalidade estadual: as normas de observância obrigatória e a defesa abstrata da Constituição do Estado-membro. São Paulo: Saraiva, 2007.

LIMA, Flavia Santiago. A Corte "Costituzionale" e suas interações no quadro institucional italiano. Revista Jus Navigandi, Teresina, ano 19, n. 4050, 3 ago. 2014. Disponível em: http://jus.com.br/artigos/30643. Acesso em: 24-06-2015.

LOEWENSTEIN, Karl. Teoría de la Constitución. (Traducción por Alfredo Gallego Anabitarte). Barcelona : Editorial Ariel, 1986.

LUCHAIRE, François. El Consejo Constitucional francés in FAVOREU, Louis. [et. al.]. Tribunales constitucionales europeos y derechos fundamentales. Madrid: Centro de Estudios Constitucionales, 2004. (Traducido por Luis Aguiar de Luque e Maria Gracia Rubio de Casas, do título original de la edición francesa: “COURS CONSTITUTIONELES EUROPENNES ET DROITS FONDAMENTAUX" bajo la dirección de Louis Favoreu, com prefacio de Andre Tunc, publicada por Presses Universitaires d' Aix-Marseille y Librairie Economica de Paris, 1982.

MACHADO, Carlos Augusto Alcântara. Mandado de Injunção: um instrumento de efetividade da Constituição. $2^{\text {a }}$ ed., São Paulo: Atlas, 2004.

MACHADO HORTA, Raul. A autonomia do estado-membro no direito constitucional brasileiro. Belo Horizonte: UFMG. Tese, 1964. 
MARINONI, Luiz Guilherme. SARLET, Ingo Wolfgang. MITIDIERO, Daniel. Curso de Direito Constitucional, $3^{\mathrm{a}}$ ed., rev., atual. e ampl. - São Paulo: Revista dos Tribunais, 2014.

MAZZEI, Rodrigo. Ações constitucionais. Org. Fredie Didier Jr. Editora Podivm, $2007-2^{\mathrm{a}}$ ed. rev. e atual.

MENDES, Gilmar Ferreira. BRANCO, Paulo Gustavo Gonet. Curso de direito constitucional, $9^{a}$ ed. rev. e atual. - São Paulo: Saraiva, 2014.

Jurisdição constitucional no Brasil: o problema da omissão legislativa inconstitucional. Artigo no site: www.stf.jus.br/arquivo/cms/noticiaArtigoDiscurso/anexo/Lituania.pdf, 2008 acesso em 24-06-2015.

Controle de constitucionalidade - aspectos jurídicos e políticos. São Paulo: Editora Saraiva, 1990.

MIRANDA, Jorge. Manual de direito constitucional, Tomo IV, Direitos Fundamentais. $3^{\text {a }}$ edição, revista e actualizada - Coimbra Editora, 2000.

MORAES, Alexandre de. Direito constitucional. - 26ª ed. - São Paulo : Atlas, 2010.

_. Jurisdição constitucional e tribunais constitucionais; garantia suprema da constituição, $3^{\text {a }}$ edição - São Paulo : Atlas, 2013.

MORTATI, Constantino. Appunti per uno studio sui rimedi giurisdizionali contro comportamenti omissive del legislatore. Foro it., 1970.

NUNES, António José Avelãs. SCAFF, Fernando Facury. Os tribunais e o direito à saúde - Porto Alegre: Livraria do Advogado Editora, 2011. 
PINA, Rolando E. Cláusulas constitucionales operativas y programáticas (Ley Fundamental de la RFA), Astrea, Buenos Aires, 1973.

PIOVESAN, Flávia. Proteção judicial contra omissões legislativas: ação direta de inconstitucionalidade por omissão e mandado de injunção. 2.ed., rev., atual. e ampl. São Paulo: Editora Revista dos Tribunais, 2003.

PIZZORUSSO, Alessandro, El tribunal constitucional italiano, in FAVOREU, Louis. [et. al.]. Tribunales constitucionales europeos y derechos fundamentales. Madrid: Centro de Estudios Constitucionales, 2004. (Traducido por Luis Aguiar de Luque e Maria Gracia Rubio de Casas, do título original de la edición francesa: “COURS CONSTITUTIONELES EUROPENNES ET DROITS FONDAMENTAUX" bajo la dirección de Louis Favoreu, com prefacio de Andre Tunc, publicada por Presses Universitaires d' Aix-Marseille y Librairie Economica de Paris, 1982, p. 233 e ss.

POLETTI, Ronaldo Rebello de Britto. Controle de constitucionalidade das leis. $2^{a}$ ed. rev. e ampl. de acordo com a Constituição de 05 de outubro de 1988, $8^{\text {a }}$ tiragem. Rio de Janeiro: Forense, 2001.

RAMOS, Elival da Silva. A inconstitucionalidade das leis - vício e sanção. São Paulo: Editora Saraiva, 1994.

RODRIGUEZ, Jose Julio Fernandez. La inconstitucionalidad por omision. Teoria general. Derecho comparado. El caso español. Madrid: Editorial Civitas, S.A., 1998.

ROTHENBURG, Walter Claudius. O Mandado de Injunção finalmente terá sua lei. In: Mandado de Injunção: estudos sobre sua regulamentação. Organizadores Gilmar Ferreira Mendes, André Rufino do Vale e Fábio Lima Quintas. São Paulo: Saraiva, 2013, p. 119-140. 
SARLET, Ingo Wolfgang. In CANOTILHO, José Joaquim Gomes.... [et al.]. Direitos fundamentais sociais - coordenadores J.J. Gomes Canotilho, Marcus Orione Gonçalves Correia e Érica Paula Barcha Correia. - São Paulo: Saraiva, 2010.

In MARINONI, Luiz Guilherme. SARLET, Ingo Wolfgang. MITIDIERO, Daniel. Curso de Direito Constitucional, $3^{\text {a }}$ ed., rev., atual. e ampl. - São Paulo: Revista dos Tribunais, 2014.

In CANOTILHO, José Joaquim Gomes. ... [et al.]. Comentários

à Constituição do Brasil. São Paulo: Saraiva/Almedina, 2013.

SCHLAICH, Klaus, EI Tribunal Constitucional Federal alemán, in FAVOREU, Louis. [et. al.]. Tribunales constitucionales europeos y derechos fundamentales. Madrid: Centro de Estudios Constitucionales, 2004. (Traducido por Luis Aguiar de Luque e Maria Gracia Rubio de Casas, do título original de la edición francesa: "COURS CONSTITUTIONELES EUROPENNES ET DROITS FONDAMENTAUX" bajo la dirección de Louis Favoreu, com prefacio de Andre Tunc, publicada por Presses Universitaires d' Aix-Marseille y Librairie Economica de Paris, 1982.

SCHWARTZ, Bernard. Direito constitucional americano. $1^{\mathrm{a}}$ edição brasileira, tradução de Carlos Nayfeld. Rio de Janeiro: Forense, julho de 1966 (de American Constitutional Law, London: Cambridge University Press, 1958).

SILVA, José Afonso da. Aplicabilidade das normas constitucionais. $8^{\mathrm{a}}$ edição. São Paulo : Malheiros Editores, 2012.

Curso de Direito Constitucional Positivo. 37. ed., rev. e atual. até a Emenda constitucional n. 76, de 28.11.2013. São Paulo, Malheiros, 2014. 
SILVA. Luis Virgilio Afonso da. O conteúdo essencial dos direitos fundamentais e a eficácia das normas constitucionais. Tese apresentada para o concurso para provimento do cargo de Professor Titular de Direito Constitucional da Faculdade de Direito da Universidade de São Paulo. São Paulo, 2005.

SOARES, Guido Fernando Silva. Common law: introdução ao direito dos EUA, $2^{a}$ ed. - São Paulo : Editora Revista dos Tribunais, 2000.

STRECK, Lênio Luiz. O mandado de injunção no direito brasileiro: análise crítica e perspectivas jurídicas e políticas. Rio de Janeiro: Edições Trabalhistas, 1991.

TAVARES, André Ramos. O cabimento do mandado de injunção: a omissão inconstitucional e suas espécies. In Mandado de Injunção: estudos sobre sua regulamentação. Organizadores: Gilmar Ferreira Mendes, André Rufino do Vale e Fábio Lima Quintas. São Paulo: Saraiva, 2013, p. 383-405.

ZAVASCKI, Teori Albino. Mandado de Injunção: anotações sobre o PL n. 6.128/2009. In Mandado de Injunção: estudos sobre sua regulamentação. Organizadores: Gilmar Ferreira Mendes, André Rufino do Vale e Fábio Lima Quintas. São Paulo: Saraiva, 2013, p. 96-100. 


\section{VIII- SITES CONSULTADOS.}

ASSEMBLEIA LEGISLATIVA DO ESTADO DE MINAS GERAIS www.almg.gov.br.

ASSEMBLEIA LEGISLATIVA DO ESTADO DE PERNAMBUCO www.alepe.gov.br.

ASSEMBLEIA LEGISLATIVA DO ESTADO DO RIO DE JANEIRO www.alerj.rj.gov.br.

ASSEMBLEIA LEGISLATIVA DO ESTADO DE SÃO PAULO www.al.sp.gov.br.

\section{CONSTITUIÇÃO PORTUGUESA}

www.parlamento.pt/Legislacao/Paginas/ConstituicaoRepublicaPortuguesa.asp.

CONSTITUIÇÃO ESPANHOLA

www.boe.es/legislacion/documentos/ConstitucionCASTELLANO.pdf.

CONSTITUIÇÃO FRANCESA - www.conseil-constitutionnel.fr/conseil -constitutionnel/root/bank_mm/portugais/constitution_portugais.pdf.

CONSTITUIÇÃO PERUANA

tc.gob.pe/portal/institucional/normatividad/constitucion.pdf.
CÂMARA
DOS
DEPUTADOS

www.camara.leg.br/internet/infdoc/novoconteudo/html/leginfra/LeginfraNao.htm.

GOVERNO FEDERAL - www.planalto.gov.br/legislacao/portallegis/legislacao-estadual/constituicoes-estaduais.

SUPREMO TRIBUNAL FEDERAL - www.stf.jus.br. 